\begin{tabular}{|l|l|l||}
\hline \multicolumn{2}{|c|}{ PublisherInfo } \\
\hline \hline PublisherName & $:$ & BioMed Central \\
\hline \hline PublisherLocation & $:$ & London \\
\hline \hline PublisherImprintName & $:$ & BioMed Central \\
\hline \hline
\end{tabular}

\title{
Surgical stress and the small intestine
}

\begin{tabular}{|l|l|l||}
\hline \multicolumn{2}{|c||}{ ArticleInfo } \\
\hline \hline ArticleID & $:$ & 4122 \\
\hline \hline ArticleDOI & $:$ & $10.1186 /$ ccf-1999-541 \\
\hline \hline ArticleCitationID & $:$ & 541 \\
\hline \hline ArticleSequenceNumber & $:$ & 59 \\
\hline \hline ArticleCategory & $:$ & Paper Report \\
\hline \hline ArticleFirstPage & $:$ & 1 \\
\hline \hline ArticleLastPage & $:$ & 4 \\
\hline \hline & $:$ & RegistrationDate : 1999-7-6 $:$ 1999-7-6 \\
ArticleHistory & $:$ & OnlineDate \\
\hline \hline ArticleCopyright & $:$ & Current Science Ltd1999 \\
\hline \hline ArticleGrants & $:$ & \\
\hline \hline ArticleContext & $:$ & 130541111 \\
\hline \hline
\end{tabular}




\section{Keywords}

Intestinal function, oxygen free radicals, surgical stress, small intestine

\section{Comments}

This study, although involving only a small number of animals, followed a logical approach to the question. The authors have been able to further elucidate the mechanisms behind the problem of intestinal failure. Their conclusions that the oxygen free radicals are involved fit well with current understanding of the chemical mediators behind multi-organ failure.

\section{Introduction}

Intestinal function can be altered by many surgical procedures. The cellular mechanism of these alterations has not been fully elucidated. As the gut is implicated in multiple organ failure (MOF), the mechanisms responsible for breakdown in intestinal barrier function are important. Previous studies have shown that bacterial translocation from the gut is induced by hemorrhagic shock. Other studies have shown that various surgical stresses, such as cholestatic jaundice and intestinal resection will alter intestinal permeability, but the biochemical basis of this is not well characterised.

\section{Aims}

To determine the structural and functional changes in rat enterocytes of the small intestine during surgical stress. The stress used was intestinal handling which would happen during the course of most major abdominal operations.

\section{Methods}


Five rats were anesthetised with ketamine and a laparotomy performed through a standard $4 \mathrm{~cm}$ vertical incision. The intestine was gently handled along its entire length while being raised from the abdominal cavity and then replaced. The whole process took 1-2 min, the abdominal wall sutured and the animals allowed to recover from anesthesia. The animals were killed 30, 60, 120 min or $24 \mathrm{~h}$ after the surgical procedure. The control animals were anesthetised in the same manner and then killed without opening the abdominal cavity.

The small intestine was removed and enterocytes isolated by the metal chelation method. The isolated enterocytes were suspended in phosphate-buffered saline solution and homogenised. The homogenate was then assayed for:

(1) xanthine oxidase and xanthine dehydrogenase activity;

(2) catalase and other thiol-dependent enzyme activity;

(3) glutathione concentration.

Conductance was measured in the whole small intestine following animal death and the mucosal tissue was examined with electron microscopy.

\section{Results}

The activity of xanthine oxidase and xanthine dehydrogenase were elevated in animals killed 60 min after laparotomy. The activity of these enzymes was returned to normal by $24 \mathrm{~h}$. This supports the involvement of increased concentrations of oxygen free radicals in the surgical stress response. Of the thiol-dependent enzymes, there was a reduction in the activity of catalase and glutathione-S-transferase at $60 \mathrm{~min}$ that recovered by $24 \mathrm{~h}$. The reduction in the activity of these enzymes indicated a decrease in the antioxidant capabilities of enterocytes, in the face of increased production of oxygen free radicals.Mucosal permeability was used as a measure of conductance. The small intestine at $30 \mathrm{~min}$ had a significant increase in conductance that reached a peak at $2 \mathrm{~h}$. After $24 \mathrm{~h}$ the conductance level reached that of controls.Histological examination showed mild widening of the basal intracellular spaces of the epithelium lining the villi at all sampling times after surgical stress. There was no apparent change in the crypt epithelium or lamina propria.

\section{Discussion}

Surgery produces altered intestinal function and the main mechanism was thought to be the surgical stress response. This has been suggested to alter microvascular perfusion and so alter intestinal function. Septic shock and surgical stress also modulate intestinal function by release of cytokines and glucocorticoids. Oxidative stress has been suggested to be involved and the free radicals released are responsible for the cellular damage seen.In this study there was an increase in the activation of xanthine 
oxidase and dehydrogenase which the authors felt was due to an increased production in oxygen free radical formation. In addition there was a reduction in the antioxidant potential of the enterocytes, as shown by the decrease in catalase activity.In conclusion, this study shows that the small intestine of the rat is susceptible to injury. Even mild handling of the gut is capable of inducing oxidative stress in the enterocyte and this produces increased permeability, probably by a widening of intracellular spaces. The maximum damage is seen at $1 \mathrm{~h}$ and recovers by $24 \mathrm{~h}$. This short time course, however, may be due to the short duration of gut handling.

\section{References}

1. Anup R, Aparna V, Pulimood A, Balasubramanian KA: Surgical stress and the small intestine: Role of oxygen free radicals. Surgery. 1999, 125: 560-569. 